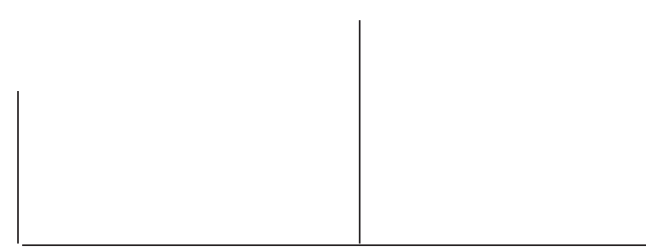

Rev. Latinoam. Psicopat. Fund., X, 3, 504-516

\title{
O raciocínio psicofarmacológico na prática psiquiátrica
}

Marcos Klar Dias da Costa

O saber na psiquiatria farmacológica é fundamentalmente empírico, devido à falta de causalidade entre os efeitos bioquímicos dos psicofármacos e as respostas psicopatológicas observadas nos pacientes. Pela necessidade de evitar associação excessiva de medicamentos e de buscar conceitos práticos para estratégias terapêuticas, um entendimento sintético é necessário. Isto é possível raciocinando-se topologicamente, usando-se um sistema de três eixos conceituais, onde as ações dos antidepressivos, dos antipsicóticos e dos estabilizadores de humor são representadas espacialmente e assim inter-relacionadas.

Palavras-chave: Psicofármacos, interação medicamentosa, prescrição médica, farmacodinâmica 


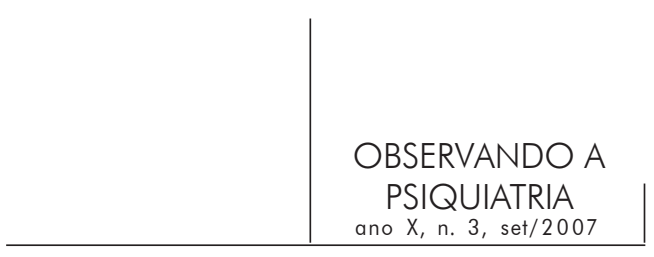

Science bestowed immense new powers on man and at the same time created conditions which were largely beyond his comprehension and still more beyond his control.

(Wiston Churchill, 1949)

\section{A dificuldade permanente na eleição de medicamentos psiquiátricos}

Uma dificuldade clássica na prática psiquiátrica é a adequada escolha das medicações para os diversos quadros clínicos, sem ter de recorrer somente a protocolos empíricos. É comum na prática substituições apressadas de medicamentos, ou seu uso em subdoses e, principalmente, a associação de psicofármacos de diferentes classes. Deniker (1972), um dos pioneiros na teorização da psicofarmacologia, já havia considerado sobre esse problema, ao estudar as associações mais ou menos viáveis entre psicotrópicos. Duas coisas concorrem negativamente para este estado da arte de prescrever: a falta de correspondência causal entre os princípios psicoativos e as modificações cognitivas e comportamentais nos pacientes - um abismo fenomenológico -, e a falta de padronização e concordância na concepção de suas propriedades funcionais - uma bruma conjetural.

Algumas divisões operacionais sugeridas aos psicofármacos foram esquecidas, tal como a diferença que se fazia entre timoanalépticos e timeréticos (Pöldinger, 1968; Spiegel, 2003a). Timoanaléptico era a denominação usada para os tricíclicos, que primordialmente teriam uma ação de elevação do humor, enquanto timerético referia-se aos inibidores da mono-amino-oxidase, os IMAO, classe química atualmente em desuso, que atuaria principalmente na desinibição geral da vigília (Guz, 1974). Por outro lado, nas últimas duas décadas os antipsicóticos foram divididos em "típicos" e "atípicos", tendo-se abandonado o termo neurolépticos para os primeiros (Marder, 2002). A diferença entre um e outro está aparentemente na ação terapêutica diferenciada, a favor dos ditos atípicos. Contudo, na prática clínica, a diferença estaria manifestamente no perfil de efeitos colaterais, neurologicamente menos tóxicos para os últimos.

Assim sendo, propomos uma orientação geral definindo classes amplas de diferentes qualidades terapêuticas na Psicofarmacologia Clínica, para depois abrir espaço e articular efeitos previsíveis na associação ou substituição de 


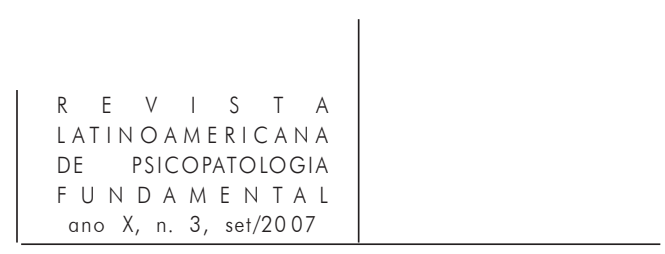

medicamentos psiquiátricos, condutas pouco claras à maioria dos que praticam a psiquiatria. Pretendemos mostrar que as regras de inclusão ou exclusão de grupos de psicotrópicos, conforme as indicações estabelecidas pela literatura médica para cada diagnóstico, devem ser flexíveis e apresentar coerência para acomodar várias possibilidades funcionalmente distintas dentro das classes terapêuticas consideradas para cada caso clínico.

\section{O abismo fenomenológico na psicofarmacologia clínica}

Um infindável precipício existe entre o aspecto microscópico e o macroscópico dos efeitos objetivos estudados no uso clínico de psicofármacos. A situação microscópica inclui a complexa interação entre estes e as moléculas biológicas envolvendo, muito além da interferência nos receptores e transportadores na neurotransmissão sináptica, mediadores intracelulares, ativação de múltiplos genes e cascatas enzimáticas, além de modificações citoarquitetônicas nos neurônios e neuróglia, promovidas por dezenas de fatores neurotróficos (Gentsch, 2003). No referencial macroscópico, há a complexa e multifatorial concorrência de variáveis psicológicas, tanto condicionadas ao ambiente social quanto determinadas pela constituição individual, como são os vínculos terapêuticos com a família e os profissionais, aliados à predisposição cultural e existencial ao tratamento e à consciência de sua necessidade. A incorporação dos pólos microscópico e macroscópico numa unidade indissociável, numa interação auto-abrangente entre os rendimentos psíquicos e substrato orgânico, onde a interferência dos medicamentos pode ou não desenvolver uma ação consistente, é um paradigma pluralista que permeia a prática médica e, em especial, a moderna psiquiatria (Ghaemi, 2003).

A ausência de correspondência linear entre os mecanismos farmacodinâmicos dos psicoativos e as manifestações das melhorias clínicas, fisiológica e psicopatológica, deve ser tida como um obstáculo relativo: embora aquela causalidade biunívoca possa nunca ser alcançada, é plausível uma associação pragmática entre os objetos bioquímicos e psicossociais a partir de uma conjetura cognitivista da ação desses fármacos no sistema nervoso que intermedeia esses dois pólos. O raciocínio deve então se pautar sobre essas representações que incorporam a resultante das ações micro e macroscópica, permitindo-se assim categorizar as classes psicofarmacológicas e a compreensão de suas direções terapêuticas. Usando ainda a metáfora do abismo, se é impossível preencher o profundo vazio entre as duas margens, torna-se viável construir pontes que substituam os saltos arbitrários e isolados em que os médicos se lançam para 


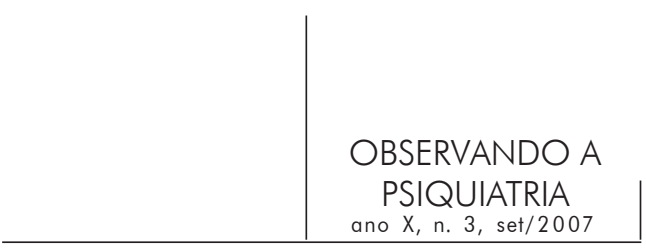

assimilar os arcanos da terapêutica química na psiquiatria. Tais pontes possibilitam a transcendência do aparente dualismo na realidade dos processos terapêuticos esperados e observados, utilizando apropriadas representações estruturalistas, que mostraremos a seguir. Elas aproximam-se mais dos fatos lingüísticos com que pacientes e profissionais descrevem a situação psicopatológica e respectivos objetivos terapêuticos, do que as terminologias aplicadas aos fenômenos moleculares e sintomatológicos.

\section{A caracterização das ações psicofarmacodinâmicas através de representações cognitivas e a superação do abismo fenomênico}

Qual é o mecanismo dos antidepressivos? E dos antipsicóticos e estabilizadores do humor? Quais são suas ações específicas e fundamentais? Embora o dualismo ainda inerente ao pensamento médico mantenha afastadas as margens do mencionado abismo, conceber que cada ser humano vive concomitantemente em dois mundos, um externo e um interno, é útil para descrever qualquer instância da existência humana (Pears, 1973). Há um orbe externo, concreto, sensorialmente organizado, e um universo particular, subjetivo e intuitivamente constituído. Conscientemente ou não, cada homem navega por esses dois planos que se sobrepõem e mutuamente se implicam, e através deles planeja sua vida e busca compreender sua realidade. Um plano não exclui o outro, sendo antes complementares (Kuhn, 2005).

Consideremos os eventos que ocorrem fora do cérebro, ou, ainda, fora do organismo de um ser humano. Eles podem ou não ser percebidos pelo indivíduo, serem ou não aferidos pelo seu Sistema Nervoso. Esses eventos podem ser interpretados em relação aos demais acontecimentos, imediatos ou passados, como sendo exteriores à realidade psíquica do indivíduo. Isto é, como se não fizessem parte de sua imaginação ou apercepção do panorama emocional e volitivo. Mas também podem ser conhecidas pelo sujeito através de modificações no seu mundo interno, por alterações nas qualidades de suas vivências, modificações aparentemente espontâneas da vida psíquica (Moizeszowicz e Moizeszowicz, 2000; Kuhn, 2005). Por outro lado, há os eventos que ocorrem na intimidade do organismo e mesmo nos meandros do próprio Sistema Nervoso, que interferem no processamento das experiências com o ambiente percebido pela pessoa. Os eventos internos podem ser vivenciados como acontecimentos externos ao psiquismo, atuando como filtro na seleção dos eventos ambientais percebidos ou emergindo à consciência como acontecimentos alheios ao organismo/ psiquismo do sujeito. Por exemplo, podemos sentir medo ou fome ao entrarmos 




em um ambiente cuja disposição possa despertar em nós tais modificações psíquicas, mesmo sem nos darmos conta dos eventos externos que levam a tais estímulos internos. Reciprocamente, alterações desencadeadas no contexto homeostático do organismo podem ser vivenciadas como fatos perceptíveis, seja de objetos presentes até então ignorados pela atenção, seja como experiências alucinatórias, com maior ou menor crítica. Deste modo, eventos intrínsecos podem manifestar-se como estímulos externos ao referencial do sujeito.

Os estímulos externos e os internos são ambos modulados pela atividade do Sistema Nervoso, como também são associados à impressão sensorial, visceral ou somática que o ambiente imprime. No prisma psicofarmacoterapêutico, parece mais adequado trabalhar com os conceitos de estímulos em vez de eventos. Esses últimos têm sua existência conceituada a partir da observação do clínico que tenta compreender os processos normais e patológicos do psiquismo que se enferma. Os eventos, intrínsecos e extrínsecos, são acessíveis ao clínico através de sua própria percepção, auxiliada ou não por instrumentos, e independem do discurso e da expressão do paciente: um eletroencefalograma, uma biópsia, ou ainda a anamnese dos fatos objetivos e subjetivos associados ao paciente. Já os estímulos são deduzidos através do discurso do paciente e de seu comportamento, informando sobre a origem e natureza de suas vivências. Sempre pressupõem a existência de um psiquismo em particular, que se busca entender através da própria unidade mental e orgânica do observador clínico (Bennett e Hacker, 2003).

Pode-se colocar então que "a ação dos antipsicóticos consiste no bloqueio dos estímulos externos; a dos estabilizadores de humor no bloqueio dos estímulos internos; e o efeito dos antidepressivos faz-se pela desinibição de recursos associativos (ou seja, pela facilitação de associações entre estímulos externos com internos, vice-versa e entre si)". Assim, entende-se que o uso de antidepressivos junto a estabilizadores de humor permite uma melhora na incorporação de estímulos externos como, por exemplo, no decorrer de uma psicoterapia. Do mesmo modo, o bloqueio tanto dos estímulos internos quanto externos numa associação entre antipsicóticos e estabilizadores do humor restringe significativamente associações inconstantes e isoladas que caracterizariam uma fuga de idéias maníaca ou uma hiperatividade histriônica.

Classificar as ações psicofarmacodinâmicas em termos cognitivistas tem a vantagem de transpor o abismo fenomenológico, subentendendo as variáveis micro e macroscópicas, e tem a conveniência de impor uma linguagem mais natural, próxima das expressões usuais que descrevem a doença e sua melhora, buscando assim dissipar a bruma conjetural. Há quarenta anos vem sendo demonstrada a conveniência de classificar os psicotrópicos pela compreensão de sua efetividade psicodinâmica em cada caso clínico, ao invés de apenas 


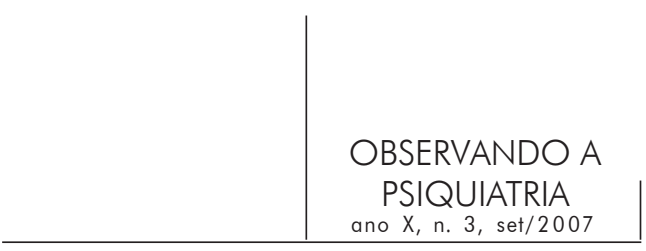

relacionálos a seu perfil bioquímico ou à sua estatística de remissão sintomática (Ostow, 1965; Kuhn, 2005).

Desfazendo a bruma conjetural: a compreensão das diretrizes psicofarmacodinâmicas pela metáfora

As medicações psiquiátricas podem ser divididas em três grandes classes, que não incluem todos os princípios ativos úteis, mas ao menos a maioria deles (Guz, 1974; Kuhn, 2005). São elas: os antidepressivos (AD), os antipsicóticos (AP) e os estabilizadores de humor (EH), estes últimos constituídos principalmente por anticonvulsivantes (AC). Os nomes são sujeitos à crítica, pois os antidepressivos não tratam somente a depressão, e os antipsicóticos podem ter outra indicação além do tratamento dos estados psicóticos. Eles descrevem as ações terapêuticas principais que seriam definidas por grupos químicos específicos. Isto constitui o primeiro postulado do construto teórico que estamos desenvolvendo: todos os antidepressivos apresentam ação terapêutica equivalente, embora alguns atuem em substratos neuronais diversos de outros e, por isso, apresentam efeitos colaterais variados, conforme a família química a que pertencem. $\mathrm{O}$ mesmo pode ser considerado em princípio para os EH (AC) e os AP.

A proposta aqui é de transformar a formulação conceitual, essencialmente técnica, destes grupos farmacológicos em uma disposição que facilita o raciocínio medicamentoso. Esta idéia não é única, como também propusera Lara (2006). Contudo, tal autor não agrupa os medicamentos em grupos funcionais, limitandose em relacionar suas ações de estimular ou inibir as características temperamentais de raiva e medo, noções criadas também para tentar superar o abismo fenomênico.

Imagine-se uma figura formada de três eixos que se irradiam de uma mesma origem (se as extremidades destes eixos forem ligadas, delinearia um triângulo equilátero), que chamaremos de eixos farmacológicos conceituais (Figura 1a). O eixo superior representa a ação dos antidepressivos e os demais a dos antipsicóticos e dos estabilizadores de humor, e a origem comum representa o estado do psiquismo atual, antes da atitude medicativa.

Quando tentamos modificar o estado mental através das intervenções psicofarmacológicas, podemos imaginar o segmento da reta correspondente mais espesso, indicando a intensidade farmacológica e respectivo efeito farmacodinâmico esperado. Veja, por exemplo, a Figura 1b, onde se representa a intervenção com um antidepressivo. 

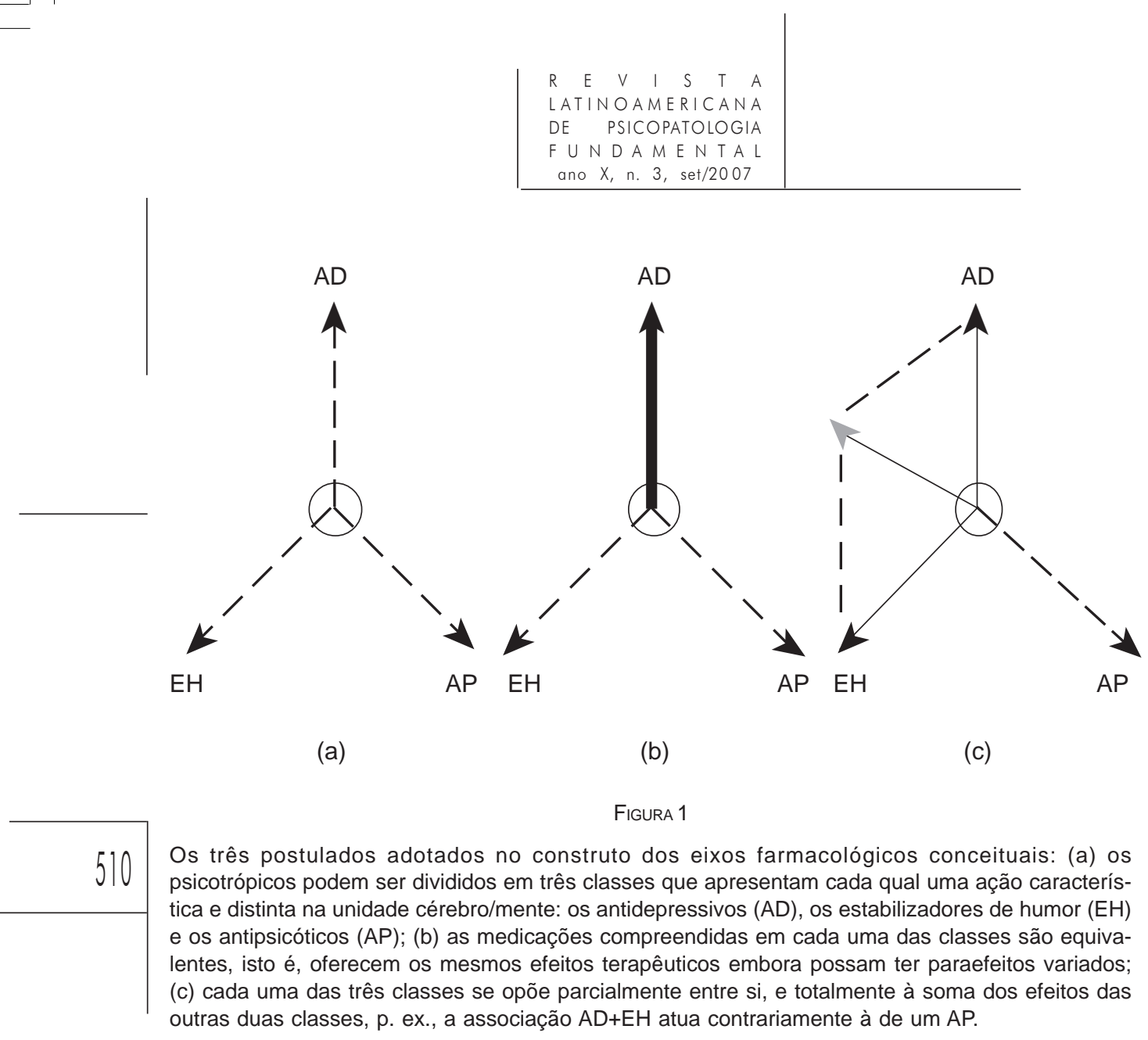

Uma segunda postulação conveniente a esse modelo é a de que cada ação farmacodinâmica opõe-se obliquamente às outras duas: o efeito antidepressivo está em relativa oposição aos efeitos antipsicótico e anticonvulsivante, sem porém ser-lhes totalmente antagônico. A reunião de dois eixos adjacentes gera uma resultante que é oposta ao terceiro eixo. Assim, por exemplo, a ação clínica da prescrição conjunta de um antidepressivo com um estabilizador de humor seria nitidamente contrária ao efeito imaginado dos antipsicóticos, como mostra a Figura 1c. De fato, sabe-se, empiricamente, que a associação de duas classes deve ser utilizada com reserva, dada a contrariedade parcial entre elas.

O modelo da Figura 1 sugere que a prescrição de todas as classes farmacológicas simultaneamente produziria resultante nula ou quase nula, mostrando-se um contra-senso. Cabe aqui uma observação sobre este construto teórico. Não é incomum encontrar pacientes usando medicamentos dos três eixos (polifarmácia), por vezes com mais de um de cada classe, que estejam controlados 


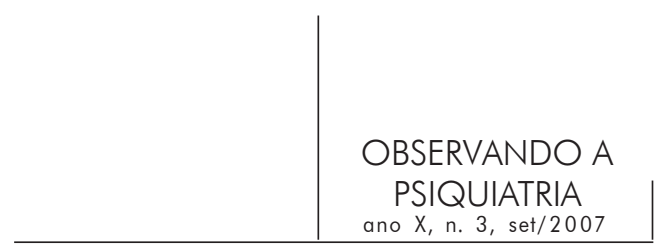

em seus sintomas mentais. Isto não invalida o que dissemos, e deve ser entendido como a preponderância de um eixo sobre os outros. Também cabe mencionar que as medicações muitas vezes nos surpreendem com a ausência de resposta ou mesmo com efeito paradoxal; e a noção empírica que as medicações têm seus efeitos individualizados e também parcialmente relacionados ao ambiente em que o paciente vive, leva a ter em conta que, teoricamente, pode-se tratar virtualmente qualquer doença mental com qualquer medicamento ou associação (Sonenreich e Kerr-Corrêa, 1985). A proposta aqui, enfatize-se, é que isso não ocorra intuitivamente ou por acaso, mas fundamentado na racionalidade de uma metodologia empírica na prática da psiquiatria.

O objetivo tão preconizado nas Escolas de Psiquiatria, aparentemente com consenso geral sobre sua necessidade, mas pouco observado a rigor na práxis, é a farmacoterapia única: usar o mínimo de medicamentos para obter a remissão clínica e a manutenção preventiva do estado mental satisfatório (Sonenreich et al., 1999). Embora haja casos em que alguns justifiquem a polifarmácia, é ética e tecnicamente plausível a suposição apriorística de que qualquer paciente em Psiquiatria pode (e deve tentar) ser medicado com uma classe farmacodinâmica - ou duas, se isto for bastante razoável - em cada etapa do tratamento.

Considerações finais

Os AP atuam bloqueando os estímulos externos que o delirante e o obsessivo incorporam em sua limitação cognitiva. Os delirantes e os alucinados podem se beneficiar da liberação dos estímulos internos para se reorganizarem quando do uso dos AP, mas não de AD. Por sua vez, os obsessivos freqüentemente melhoram com $\mathrm{AD}$, que permitem que haja reorganização mental a partir de novas referências interiores aos fatos incorporados nos rituais (Bassit et al., 1992). Talvez o fato de terem sua crítica preservada, diversamente dos esquizofrênicos ativos, permita essa recuperação com os AD. Na depressão e na ansiedade, os $\mathrm{AD}$ reativam associações provocando uma desinibição geral. O resgate de recursos, até então suprimidos, pelos AD pode ajudar semelhantemente os astênicos (Sonenreich et al., 1991).

O tratamento clássico para os quadros maníacos são basicamente os EH, que atuam reduzindo a atividade multiplicadora de associações cognitivas. Os bloqueadores de estímulos externos também manifestam um efeito antimaníaco. Ambos os bloqueadores reduzem a atividade associativa anormal do Sistema Nervoso.

Alguns AP têm ação levemente estimulante, como a amissulprida e a sulpirida, e os AC como a lamotrigina e carbamazepina (Lafer, 1998), também 


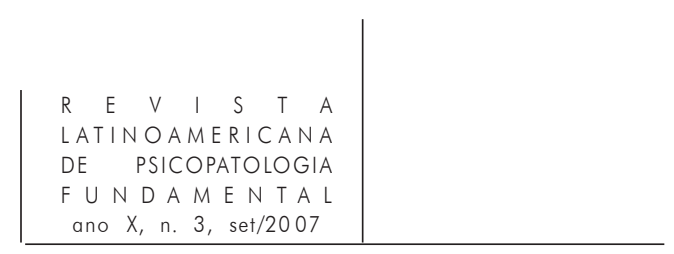

têm efeito similar. Certos AD são mais ativadores, outros mais ansiolíticos. Contudo, o fato de as diversas substâncias terem peculiaridades não elimina sua propriedade essencial, que é definida pela classe a que elas pertencem.

Os psicoestimulantes (no Brasil, só o metilfenidato) comportam-se como um facilitador de estímulos externos, numa ação contrária à dos AP sem ser exatamente equivalente à soma de um $\mathrm{EH}$ e um $\mathrm{AD}$ na prática. As anfetaminas de uso anorexígeno são facilitadores mais potentes e atuam inibindo a apercepção de eventos intrínsecos do organismo, como libido, fome e sono, sem contudo bloquear os estímulos internos, pois aumentam a irritabilidade e a labilidade afetiva. Os psicoestimulantes poderiam ser considerados, para efeito do nosso constructo, um grupo especial de AD, ou mesmo de EH. Como seu uso na psiquiatria parece ser bastante restrito ao transtorno de déficit de atenção e hiperatividade e, ocasionalmente, como coadjuvante na depressão ou astenia, não merecem maiores preocupações (Spiegel, 2003b).

Do mesmo modo os anticolinesterásicos, de eficácia ainda questionável, usados nos quadros incipientes de síndromes demenciais, apresentam um perfil de indicações muito limitado. Como regra geral antiga dos intensivistas, as drogas que facilitam a ação da acetilcolina se opõem funcionalmente às que facilitam a ação da dopamina; portanto, os anticolinesterásicos, que facilitam o efeito colinérgico, atuariam no eixo AP (Eisendrath, 1994).

Os eventos intrínsecos mais importantes são as modificações na atividade cerebral a partir da dinâmica das associações vivenciais (recursos associativos) estabelecidas e continuamente corrigidas ou confirmadas pela vida psíquica. Isto permite que essas associações sejam ativadas ou inibidas para manter um contexto apropriado para a recepção de estímulos e elaboração e seleção das respostas do organismo a tais estímulos. Essas associações, quando saudáveis, devem ser suficientemente móveis e estáveis para permitir que o meio interior possa lidar com a maior ou menor previsibilidade dos fatos do ambiente exterior, integrando o sujeito e seu mundo. Os recursos associativos devem ser móveis para acompanhar alterações dos estímulos e as ocasionais respostas para manter essa correspondência sempre abrangente e atualizada; e devem ainda ser estáveis para preservar padrões constantes, que precisam permanecer por mais ou menos tempo, apesar das mudanças nos estímulos ou respostas. Assim, uma qualidade modifica a outra e essa dialética permite a sobrevivência de um psiquismo sadio.

Os estímulos internos podem ser bloqueados através de inibição da hiperatividade do Sistema Nervoso. Essa ativação anormal pode ser devida basicamente por associações vivenciais imóveis persistentes ou por recursos associativos instáveis abundantes. A menor mobilidade associativa está relacionada com doenças com substrato neurológico como epilepsias, traumatismos cranianos, processos expansivos, seqüelas meningíticas, encefalopatia alcoólica, 


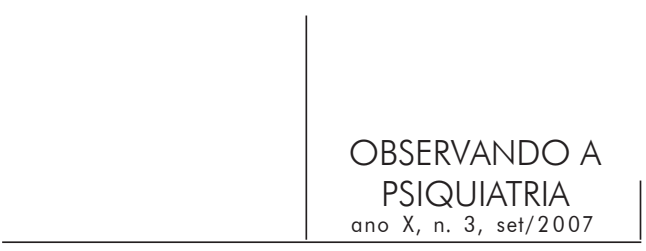

autismo, retardo mental, acidentes vasculares etc. A atividade desmedida de associações instáveis ocorre mais agudamente e relaciona-se mais a distúrbios de etiologia freqüentemente psiquiátrica, como os transtornos bipolares, caracteristicamente os quadros maníacos, bem como os casos de intensa astenia neuropsicológica.

A classe dos estabilizadores de humor na verdade compõe-se de dois grandes grupos de medicamentos: os anticonvulsivantes (AC) e os pró-convulsivantes (PC). Os primeiros caracteristicamente compartilham sua utilidade na Neurologia pelo tratamento de convulsões, como na epilepsia. Os PC incluem basicamente a associação de $\mathrm{AP}$ e AD, o lítio, a eletroconvulsoterapia (ECT) e, outrora, o choque cardiazólico e a insulinoterapia. Os AC agem bloqueando estímulos internos gerados por associações vivenciais estanques, que tendem a ser mais antigas e permanentes. Os PC atuam sobre estímulos internos relacionados com associações recursivas instáveis, logo de surgimento mais recente e duração mais breve.

A ECT é bastante eficaz em alterações profundas e agudas da vida psíquica, sendo pouco ou nada efetiva em quadros crônicos (Sonenreich e Kerr-Corrêa, 1985). Como o lítio, é bastante eficiente na profilaxia e reversão de quadros maníacos e depressivos de rápida evolução, compatíveis com a liberação de associações instáveis corticais e subcorticais. A depressão psicótica, isto é, depressão que evolui com sintomas delirantes-alucinatórios, pode responder tanto à ECT quanto à combinação AP+AD. Há trinta anos esta associação era indicada para tratamento de sintomas negativos na esquizofrenia (Deniker, 1972). Nos casos de mania de características atípicas, neurológicas (que inclui estados mistos com depressão, ciclagem rápida, antecedentes neuropáticos etc.) a resposta costuma ser melhor com anticonvulsivantes (Lafer, 1998), talvez devido a um prejuízo maior por associações patológicas imóveis do que pelas instáveis. Assim, tanto os processos de instabilidade recursiva quanto os de imobilidade podem estar envolvidos em um mesmo quadro clínico. A insulinoterapia por muitas décadas prestou-se a reverter quadros de esquizofrenia de evolução delirante subaguda, possivelmente compensando grandes desorganizações por astenia neuropsíquica, através de um processo de reorganização maciça do Sistema Nervoso, como na insulinoterapia (Sonenreich et al., 1999). Embora sua classificação como pró-convulsivante indique uma redução no limiar convulsivo, é relevante o efeito comum em geral contrário à ação antiepiléptica dos AC.

Os benzodiazepínicos, embora quimicamente antiepiléticos, são estabilizadores de humor pouco eficazes, até mesmo questionáveis: é classicamente descrita a reação paradoxal, mormente em crianças, idosos e portadores de patologias cerebrais, com agitação, ansiedade e confusão mental (Spiegel, 2003a). É legítimo compreender seu mecanismo farmacodinâmico 


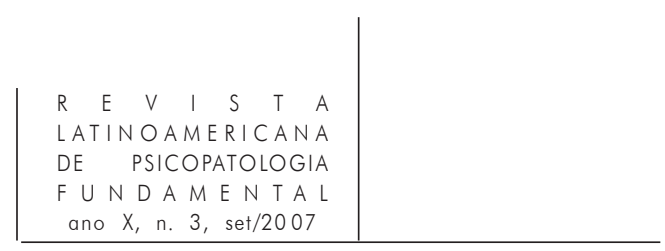

através de uma desinibição das associações instáveis mais que a inibição de recursos imóveis. Seu uso como ansiolítico pode oferecer por tempo breve uma melhoria que é mais longa com os AD.

Finalmente, alguns medicamentos, como os antiparkinsonianos, os betabloqueadores, os agonistas dopaminérgicos e os anti-histamínicos, são utilizados na prática psiquiátrica para deter efeitos colaterais neurológicos dos psicotrópicos e não necessitam ser enquadrados em eixos farmacodinâmicos.

Naturalmente, quanto mais se tenta adequar racionalmente a polifarmacoterapia, tanto maior será a dificuldade em dispor de uma estrutura teórica que resolva as aparentes contradições das associações medicamentosas. O importante sempre será o clínico ter um bom vínculo com seu paciente que permitirá um trabalho lúcido e orientado, em que o raciocínio psicofarmacológico deve ser aliado seguro para o sucesso terapêutico e nunca um empecilho maior que a doença. Acima de tudo, deve haver o compromisso de usar, sem abusar, responsavelmente.

\section{Referências}

BAssit, Wiliam et al. Caos, Fractal e Psiquiatria. Temas. São Paulo, v. XXII, n. 44, p. 161170, jul./dez. 1992.

Bennett, Maxwell R. e Hacker, Peter M. S. Philosophical Foundations of Neuroscience. Padstow: Blackwell Publishing, 2003.

Deniker, Pierre. Psychopharmacologie et Pharmaco-psychiatrie. Confrontations Psychiatriques, Paris, n. 9, p. 9-29, 1972.

Eisendrath, Stuart J. Psychiatric problems. In: Bongard, Frederic S. e Sue, Darryl Y. Current Critical care Diagnosis and Treatment. Londres: Prentice Hall International, 1994.

Ghaemi, S Nassir. The Concepts of Psychiatry: A Pluralistic Approach to the Mind and Mental Illness. Baltimore: The Johns Hopkins University, 2003.

Gentsch, Conrad. Preclinical research in psychopharmachology. In: Spiegel, René. Psychopharmacology an Introduction. Chichester: John Wiley \& Sons, 2003.

Guz, Isac. Terapêutica biológica nos distúrbios mentais. São Paulo: Artes Médicas, 1974.

Kunn, Roland. Psicofarmacologia e análise existencial. Revista Latinoamericana de Psicopatologia Fundamental, São Paulo, v. VIII, n. 2, p. 221-2, jun./2005.

LAFER, Beny. Novos antidepressivos e estabilizadores de humor. Simpósio Internacional O futuro da Neuropsiquiatria, São Paulo, mar. 1998. 
LARA, Diogo. O modelo de medo e raiva para os transtornos de humor, do comportamento e da personalidade. Porto Alegre: Revolução de Idéias e Editorial, 2006.

Marder, Stephen R. Medicações antipsicóticas. In: Schatzberg, Alan F. e Nemeroff, Charles B. Fundamentos de psicofarmacologia clínica. Rio de Janeiro: Guanabara Koogan, 2002.

Moizeszowicz, Julio e Moizeszowicz, Mirta. Psicofarmacología y territorio freudiano: teoría y clínica de un abordaje interdisciplinario. Buenos Aires: Paidós, 2000.

Ostow, Mortimer. Method and madness: a critique of current methodology in psychiatric drug research. Journal of clinical pharmacology, v. 5, n. 1, p. 3-8, jan./fev. 1965.

PEArs, David. As idéias de Wittgenstein. São Paulo: Cultrix, 1973.

Pöldinger, Walter. Compêndio de psicofarmacologia. Basiléia: F. Hoffman-La Roch \& Cie, 1968.

Sonenreich, Carol e Kerr-CorrêA, Florence. Escolhas do psiquiatra: saber e carisma. São Paulo: Manole, 1985.

Sonenreich, Carol et al. Debates sobre o conceito de doenças afetivas. São Paulo: Manole, 1991.

Psiquiatria: propostas, notas, comentários. São Paulo: Lemos, 1999.

SPIEGEL, René. Modern psychopharmaceuticals. In: Psychopharmacology an introduction. Chichester: John Wiley \& Sons, 2003a.

Effect of psychotropic medication on healthy subjects. In: Psychopharmacology an introduction. Chichester: John Wiley \& Sons, 2003b.

\section{Resumos}

El conocimiento en psiquiatría farmacológica es básicamente empírico debido a la falta de causalidad entre los efectos bioquímicos de los psicofármacos y las respuestas psicopatológicas observadas en los pacientes. Para evitar prescribir asociaciones excesivas de psicoactivos y buscar conceptos prácticos para estrategias terapéuticas se proponen tres ejes equidistantes donde las acciones de los antidepresivos, los antipsicóticos y de los estabilizadores del humor se arreglan espacialmente y así se relacionan.

Palabras claves: Psicofármacos, interacción medicamentosa, prescripción médica, farmacodinamica 


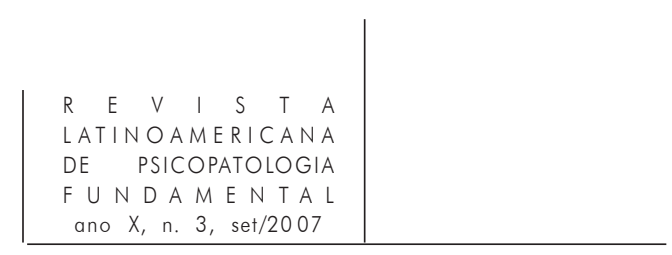

La connaissance en psychiatrie pharmacologique est surtout empirique à cause du manque de la causalité entre les effets biochimiques des médicaments psychotropes et les réponses psychopathologiques observées dans les patients. Pour éviter les associations excessives entre ces médicaments et pour pouvoir développer des concepts pratiques pour les stratégies thérapeutiques, on propose trois axes équidistants où les actions des antidépresseurs, des antipsychotiques et des stabilisateurs de l'humeur sont spatialement étalées et mises en rapport.

Mots clés: Médicaments psychotropes, interaction médicamenteuse, prescription médique, pharmacodynamie

Knowledge in pharmacological psychiatry is basically empirical, due to the lack of clear causality between the biochemical effects of psycho pharmaceutical products and the psychopathological responses of the patients. In order to avoid prescribing excess drugs and to search for practical concepts for therapeutic strategies, three equidistant areas are presented where antidepressant drugs, antipsychotic drugs, and mood stabilizers are arranged spatially and thus related to one another.

Key words: Psychiatric drugs, drug interactions, medical prescription, pharmacodynamics 